\title{
Hybrid Energy Piles as a Smart and Sustainable Foundation
}

\author{
Gianpiero Russo ${ }^{1} \odot$, Gabriella Marone ${ }^{1^{*}}$, Luca Di Girolamo $^{1}$ \\ ${ }^{I}$ Department of Civil, Architectural and Environmental Engineering, Polytechnique and Basic Sciences School, University of Napoli \\ Federico II, Via Claudio 21, 80125, Napoli, Italy
}

Received 29 June 2021; Revised 19 August 2021; Accepted 25 August 2021; Published 01 September 2021

\begin{abstract}
The disused factories' areas represent a considerable part of the industrial archaeology of the city of Naples. In the last decades of the previous century, many of these factories were disused because of the ban on asbestos production by Italian law 257/1992. Of course, this was not the only problem that concurred to create a large number of disused industrial areas. Often the simple delocalization of manufactories in other countries contributed to this problem. The reuse of these areas requires polluted and contaminated land reclamation. The simple removal of the shallow soil layers is a widely used reclamation procedure. Furthermore, drilling operations either for piling or for tunneling may incur the same type of problem, taking into account that this movement can be very expensive depending on the total volume of soil to be removed and to be taken to disposal. In this study, a hybrid pile type is proposed as an environmentally friendly and cheap solution. Hybrid piles are installed by a combination of pushing and augering techniques. This installation method allows avoiding the removal and subsequent disposal of shallow contaminated soil. The mechanical behaviour of three hybrid piles equipped with strain gauges along the shaft is investigated via three loading tests. In the framework of the design of a new mall in a disused industrial area, the opportunity to provide a fully sustainable foundation solution by equipping the piles with heat exchanger pipes is also being investigated. Numerical simulations of the energy hybrid pile behaviour are presented, outlining further benefits of the new hybrid installation technique and comparing two different configurations of the heat exchanger pipes.
\end{abstract}

Keywords: Hybrid Energy Piles; Sustainable Foundations; Thermo-mechanical Behaviour; Geothermal Energy; Industrial Sites Contamination.

\section{Introduction}

An issue of concern around the world is the contamination of industrial sites. These soils, indeed, could be an issue of concern around the world. Because they could have high contents of different types of industrial pollutants coming from processes metallurgy, chemical industry, and dyeing [1]. Despite the kind and concentration of contaminates generally, the reclamation of these soils could be done by physical, chemical, or biological processes [2]. At first, field tests and surveys are needed to obtain a precise map of the pollutants present and the status of the site under examination [3]. Compared to air and water, soil contamination is not so evident to observe. It is called "invisible contamination" and can be very harmful to human health [1].

Soil replacement and thermal desorption processes are included in the physical methods of soil reclamation. The former uses clean soil for a partial or total replacement of polluted soil [4]. According to the temperatures, thermal desorption can be divided into low temperature $\left(90-320^{\circ} \mathrm{C}\right)$ and high temperature desorption $\left(320-560^{\circ} \mathrm{C}\right)$. This

\footnotetext{
* Corresponding author: gabriella.marone@unina.it

doi) http://dx.doi.org/10. 28991/HEF-2021-02-03-010

$>$ This is an open access article under the CC-BY license (https://creativecommons.org/licenses/by/4.0/).

(C) Authors retain all copyrights.
} 
technique consists of heating contaminated soil in thermal desorber to volatile the pollutants that are captured by specific equipment $[1,4]$. In addition to heavy metals, other highly dangerous soil contaminants for human health are organic contaminants such as Polycyclic Aromatic Hydrocarbons (PAHs) that accumulate in urban soils and could be transferable into the human body via ingestion, inhalation, and dermal contact. Some of the PAHs are human carcinogens [5].

The municipalities on the outskirts of the city of Napoli had an intense development of industrial activities in the immediate post-war period. Industrial activities were mainly petrochemical, iron and steel, or energy companies. Since the eighties, many of these factories have often been abandoned, leaving behind considerable problems of dismantling, demolition, and reclamation [3]. Soil removal by excavation can be one of the main remediation techniques, or at least a phase of the soil replacement remediation technique. This procedure, prior to 1984, was the most common for cleaning up contaminated sites. It is appropriate only for a small area in the case of heavily contaminated soils and is very expensive depending on the transportation costs of the soil removed [2].

Sometimes the contaminated soil is not dangerous; however, the soil is excavated in the framework of drilling activities, either for piling or for tunnelling. In such a case, at the design stage, an important cost is that arising from the need to transport the excavated soil to the authorized waste disposal site, which in turn depends on the type of pollutants diffused in the soil mass. A new mall and a touristic facility are under construction at Torre Annunziata, south of Napoli, close to the Pompeii archaeological park. The area is in the plain south-east of Somma-Vesuvius where the subsoil is composed mainly of products of the volcanic activity and was occupied until ten years ago by a pipe factory (Figure 1 (a) and (b)).

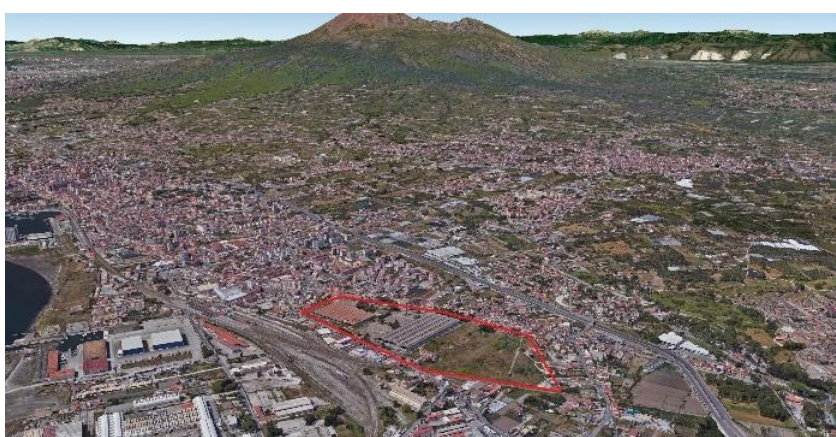

(a)

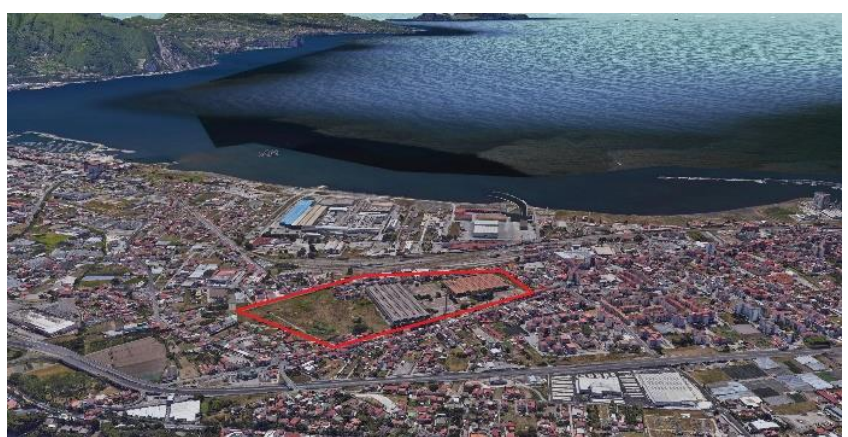

(b)

Figure 1. Site location. (a) Vesuvius volcano view and (b) gulf of Napoli view

\section{Hybrid Energy Piles as a Sustainable Foundation of the New MaxiMall-Pompeii}

When piles are selected as foundations for a new building a decision about the pile type shall be taken at the design stage. In terms of piling installations two main categories of piles are usually considered: driven or pushed and bored or drilled piles. More recently the name of these categories has been substituted by new terms: replacement piles or displacement piles. Replacement piles are those ones which require excavation and the soil is removed for installing the pile in the ground. Displacement piles are those ones which do not require excavation and consequently soil is not extracted. The pile is installed by simply displacing the soil mass densifying the surrounding soil. In this second option there is no soil to be transported to waste disposal. There are, in addition, intermediate pile types as partial displacement piles (so-called large stem auger piles) or nearly fully bored piles as continuous flight auger piles, CFA piles, installed by combining driving and augering techniques. Different pile types are available on the market and they are, generally, selected on the basis of subsoil conditions and of the foundation design needs. In simple words displacement piles have typically better geotechnical performance but they are not suited for stiff or dense soils and in the case of even partial cementation degree. With reference to a new mall under construction in the area of Pompei archaeological ruins, the shallow layer was possibly contaminated being an industrial disused area. Furthermore, the shallow layer was very soft, while, on the other hand, the subsoil below 6-8 $\mathrm{m}$ was rather stiff and partially cemented due to the volcanic origins and the high temperature at the time of areal deposition. For both reasons at the design stage a hybrid pile was purposely conceived. In the picture (b) of Figure 2 the piling machine is reported. The upper part of the pile is a typical large stem pipe pile with the pipe simply pushed in the ground without soil removal while the lower part is a classical CFA pile with a significant volume of soil removed in the step when the installation tool is retrieved upwards. The hybrid technique adopted thus allowed a double benefit. First of all, a better mechanical performance in the upper soft layers due to the displacement type of pile which induce soil densification. Second the soil removed is only relative to the lower part of the pile in the deeper soil layers which are not contaminated.

In the frame of the design stage of the pile foundations of a new large Mall the mechanical performance of this new pile type has been tested with three design loading tests. Pile load- settlement relationships, bearing capacity and load transfer curves of the side shear, obtained from the experimental campaign, are discussed. Starting from the purely 
mechanical response observed during the loading tests, a FE axi-symmetrical model was calibrated. Transient thermohydro-mechanical analyses are then used to simulate the behaviour of an isolated hybrid pile subjected to thermomechanical loadings. In this study, two possible configurations of the primary circuit for heat exchange are proposed and compared. The Case A is a pile where only the bottom replacement part of the foundation pile (the part excavated with the auger) is equipped with the HDPE [6] close to the reinforcement cage (Energy piles). The Case B is a conventional energy pile with all the shaft equipped with HDPE plastic pipes.

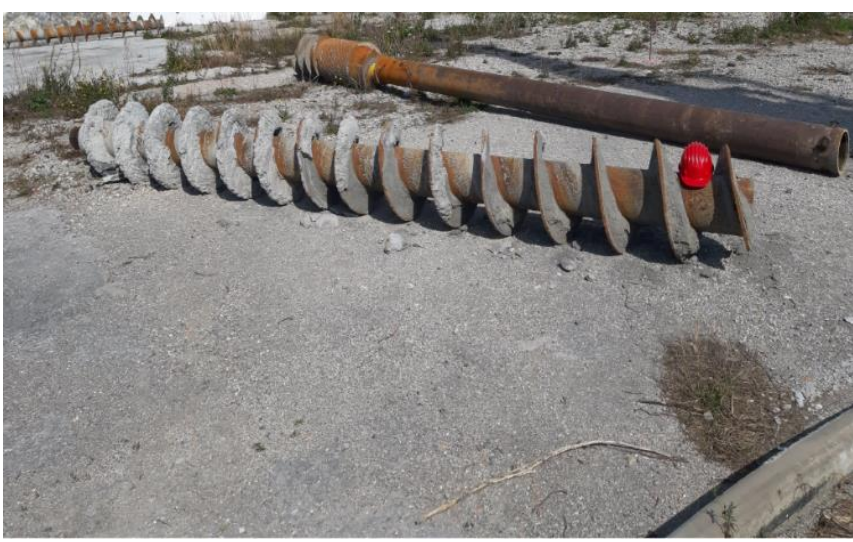

(a)

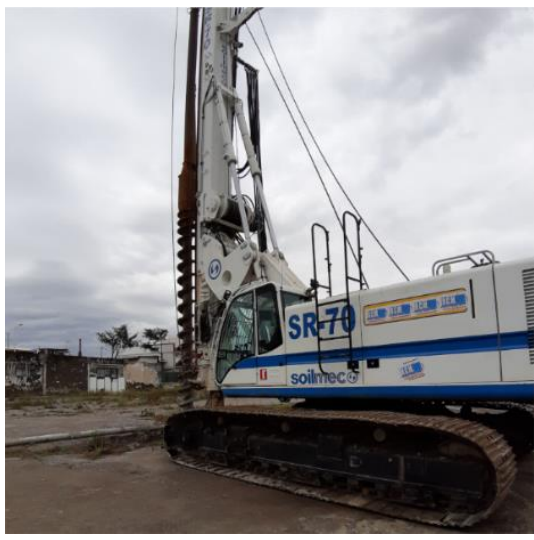

(b)

Figure 2. Piling rig for hybrid pile. (a) Combination of Continuous Flight Auger and Large stem displacement pile and (b) hydraulic drilling rig

\section{Subsoil Conditions and Pile Loading Tests}

The site is located at the feet of Vesuvius volcano and the subsoil is made mainly by products of the volcanic activities. On this area there was a disused factory called before Ital-Tubi and after Vega Tecnotubi. The history of the factories activities in this area is an old one and spans over more than one century with several stops. For instance, two stops occurred during the two world wars. The last activity in the area was pipe production by the Italtubi Company. From the Regional Reclamation Plan resulted that the soil of the area could be possibly contaminated by PAHs, (metals and non-metals, inorganic compounds, and hydrocarbons. Regional Reclamation Plan was issued in 2013 and updated on 30/12/2019 according to the provisions D.Lgs. 152/2006. In this plan, the contaminated and potentially contaminated sites of the region were updated and for some areas only a general warning was issued about the need for chemical analyses of soil to be removed. As already anticipated in the previous section this suggested the use of displacement piles instead of replacement piles at least for the top layer about 7-8 $\mathrm{m}$ deep. From the geotechnical point of view, site investigations carried out are:

- $\mathrm{N}^{\circ} 8$ continuous coring boreholes (S1 to S5 $33 \mathrm{~m}$ deep and S6 to S8 $25 \mathrm{~m}$ deep),

- $\mathrm{N}^{\circ} 8$ Down-hole geophysical tests (from S1 to S8),

- $\mathrm{N}^{\circ} 7$ Standard penetration tests,

- $\mathrm{N}^{\circ} 12$ Cone Penetration Tests -CPTU,

- $\mathrm{N}^{\circ} 2$ Casagrande type piezometers for the groundwater table investigation.

A plan view of the test site with the locations of the main site investigations is reported in Figure 3.

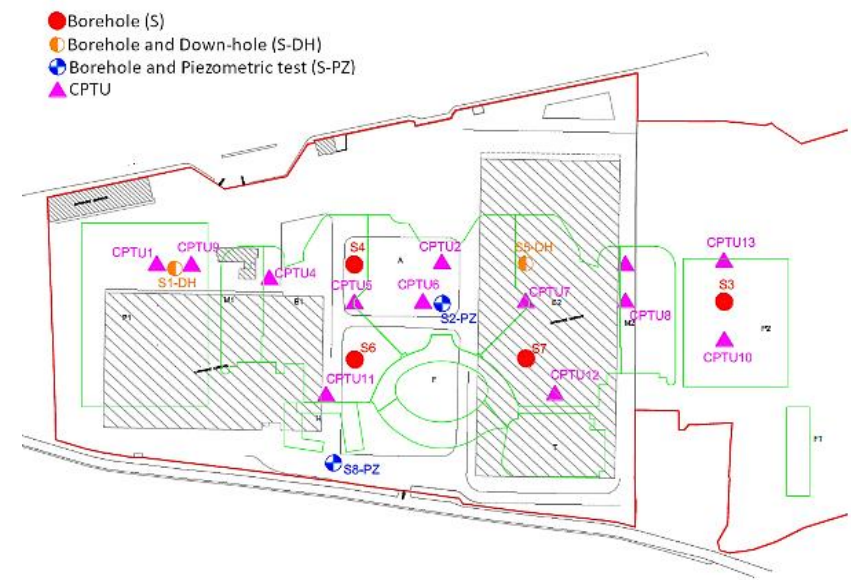

Figure 3. Plan view of the site with the locations of test investigations 
CPTs and SPTs investigations allow determining the cone tip resistance $\mathrm{Q}_{\mathrm{c}}$ and the blow count $\mathrm{N}_{\mathrm{SPT}}$. The obtained cone tip resistance and the blow count are reported in Figure 4 (a) and (b), respectively. SPTs were stopped at 50 blows as shown in Figure 4 (a). From Figure 4 (b) it is possible to notice that CPTs were stopped between $7 \mathrm{~m}$ and 10 $11 \mathrm{~m}$ because coarse material (i.e. sandy soil with pumices) was encountered.

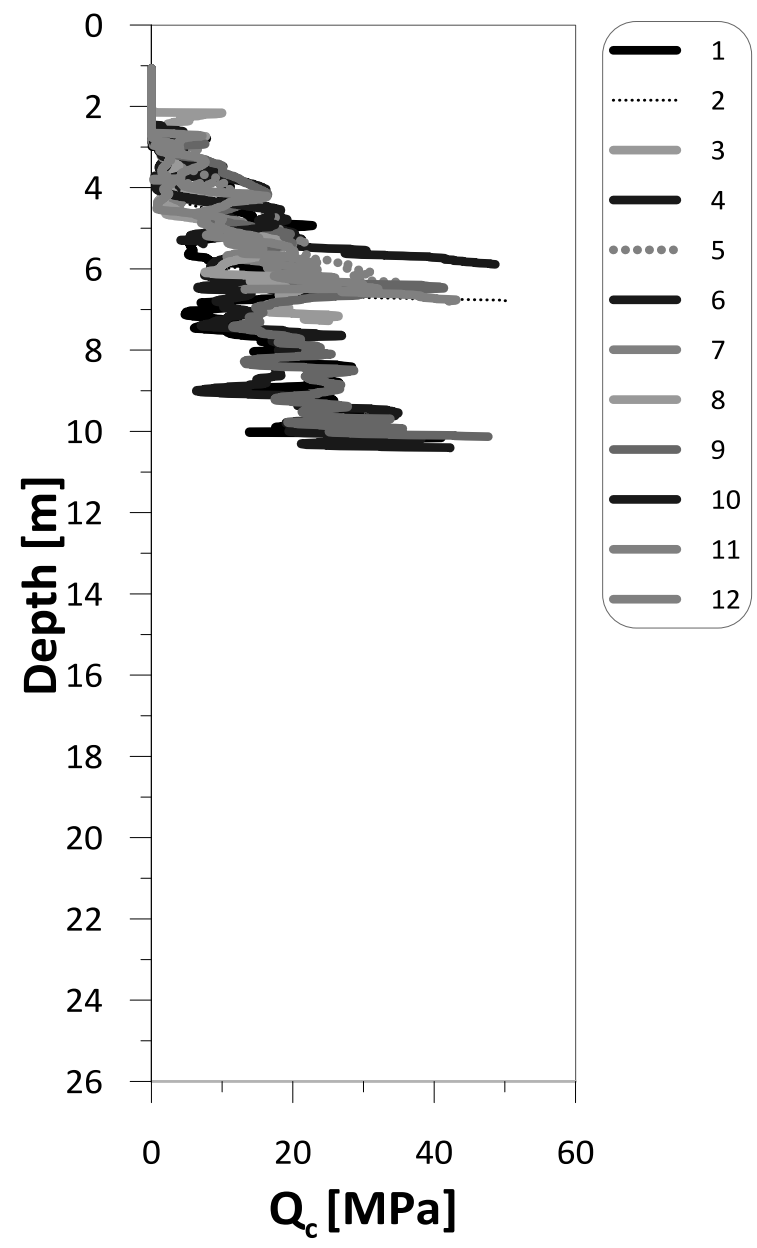

(a)

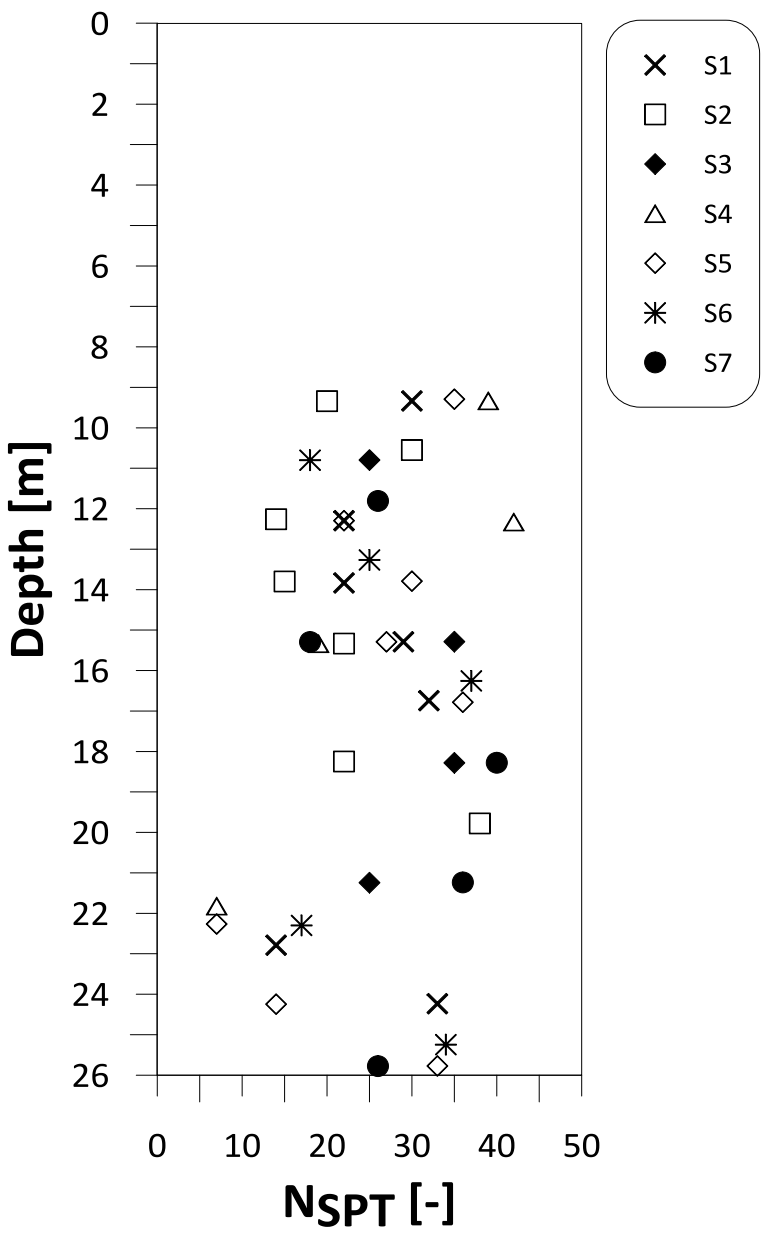

(b)

Figure 4: Site investigations results (CPTs and SPTs). (a) Resistance of the static penetrometer at the toe (Qc) versus soil depth and (b) Blow count (NSPT) versus soil depth

An empirical correlation between the ratio of cone tip resistance and blow count and median diameter of soil particles, $\mathrm{D}_{50}$, was used to evaluate the expected $\mathrm{Q}_{\mathrm{c}}$ below $11 \mathrm{~m}$ from the ground surface. The results from CPTs and SPTs allowed the determination of soil stiffness and strength parameters. Relative density for each soil layer was computed through Gibbs and Holtz (1957) and Kulhawy and Mayne (1990) [7, 8] expressions considering the mean blow count and cone tip resistance $\mathrm{Q}_{\mathrm{c}}$, respectively, for each soil layer. Friction angle for each soil layer was computed as mean value between those obtained from API (1987) and Schmertmann (1979) [9, 10] relationships considering the average relative density. For each soil layer secant Young modulus Es was obtained from De Beer (1965) [11]. Soil physical and mechanical properties are thus summarised in Table 1.

Table 1. Soil layering and mechanical properties

\begin{tabular}{|c|c|c|c|c|c|c|c|c|}
\hline \multirow{2}{*}{ Layer } & \multirow{2}{*}{ Soil Type } & \multicolumn{2}{|c|}{ Depth } & \multirow{2}{*}{$\underset{\left(k N / m^{3}\right)}{\mathbf{Y}}$} & \multirow{2}{*}{$\begin{array}{c}\varphi \\
\left(^{\circ}\right)\end{array}$} & \multirow{2}{*}{$\begin{array}{c}\mathrm{C}^{\prime} \\
(\mathbf{k P a})\end{array}$} & \multirow{2}{*}{$\begin{array}{c}\mathbf{E}_{\mathrm{s}} \\
(\mathbf{M P a})\end{array}$} & \multirow{2}{*}{$\begin{array}{c}\mathbf{E}^{*_{0}} \\
(\mathbf{M P a})\end{array}$} \\
\hline & & Top (m) & Bottom (m) & & & & & \\
\hline 1 & US & 0 & 1 & 18 & 30 & - & 10 & - \\
\hline 2 & $P 1$ & 1 & 3 & 16 & 32 & - & 20 & 180 \\
\hline 3 & $S G$ & 3 & 10 & 17,5 & 35 & - & 45 & 460 \\
\hline 4 & $P 2$ & 10 & 12 & 16 & 32 & - & 35 & - \\
\hline 5 & $F S$ & 12 & 22 & 17 & 35 & - & 50 & 850 \\
\hline
\end{tabular}

* Obtained by Down-hole geophysical tests. 
Three design load tests kept to failure were performed on three model piles (Pile 9, Pile 8 and Pile 7). Each pile was installed in a different area of the rather large site corresponding to different superstructures to be constructed (Figure $5)$ :

- Parking Area (P1) for load test on Pile 9,

- Central MallArea for load test on Pile 8,

- Multi-storey car Parking Area (P2) for load test on Pile 7.

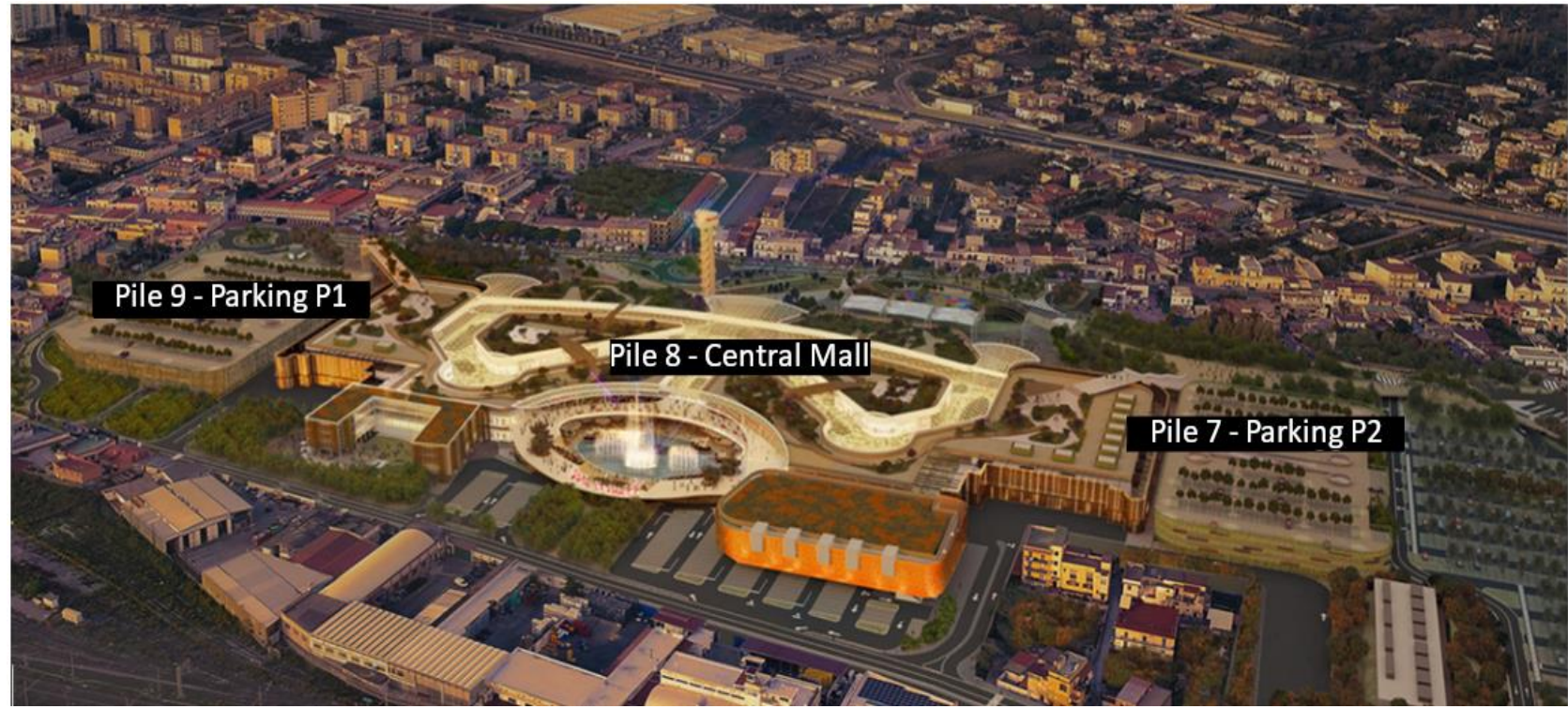

Figure 5. Aerial view of the final layout of the area with its two parking facilities and the central Mall

In Figure 6 the layout of a typical pile loadings test is reported via pictures and a drawn sketch. As shown by the figures it is a loading test where the reaction to the compressive load on pile is obtained via a thick spreading beam anchored to a couple of tension piles located at the two opposite sides from the pile to be tested [12]. The load is applied by means of a hydraulic jack placed at pile head on a $20 \mathrm{~mm}$ thick steel plate. The tension piles are reinforced with six Dywdag bars of $40 \mathrm{~mm}$ diameter. The vertical load applied on the central pile is measured trough a load cell while pile's head settlement is measured through four linear variable displacement transducers (LVDTs) and a redundant precision optical survey. A benchmark sufficiently far away from the area of the test is adopted as fixed reference point. LVDTs react on a steel reference beam, resting on supports fixed to the soil at sufficient distance to avoid interaction.

During the tests carried out at the design stage, the axial strains along the shaft were also measured. Vibrating wire strain gauges of the type for embedding in concrete were used and installed according to the technique proposed by Russo (2004) [13]. For each test pile, six strain gauges were installed by fixing them at the desired intervals to a rope, tensioned by a weight at the bottom, and lowered in position into a pipe before filling it from the bottom through a flexible plastic pipe, progressively withdrawn (Figure 7(a)). No-shrinkage cement grout was employed to ensure full adhesion between the grout and the pipe [13]. Figures 7(b), (c) and (d) show the strain gauges position along pile shaft for each model pile.

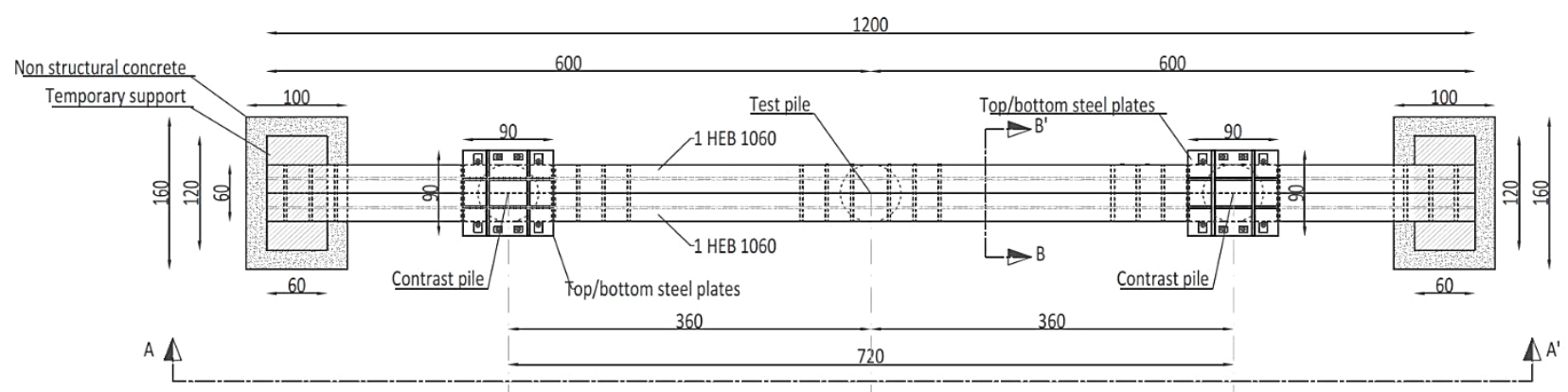

(a) 


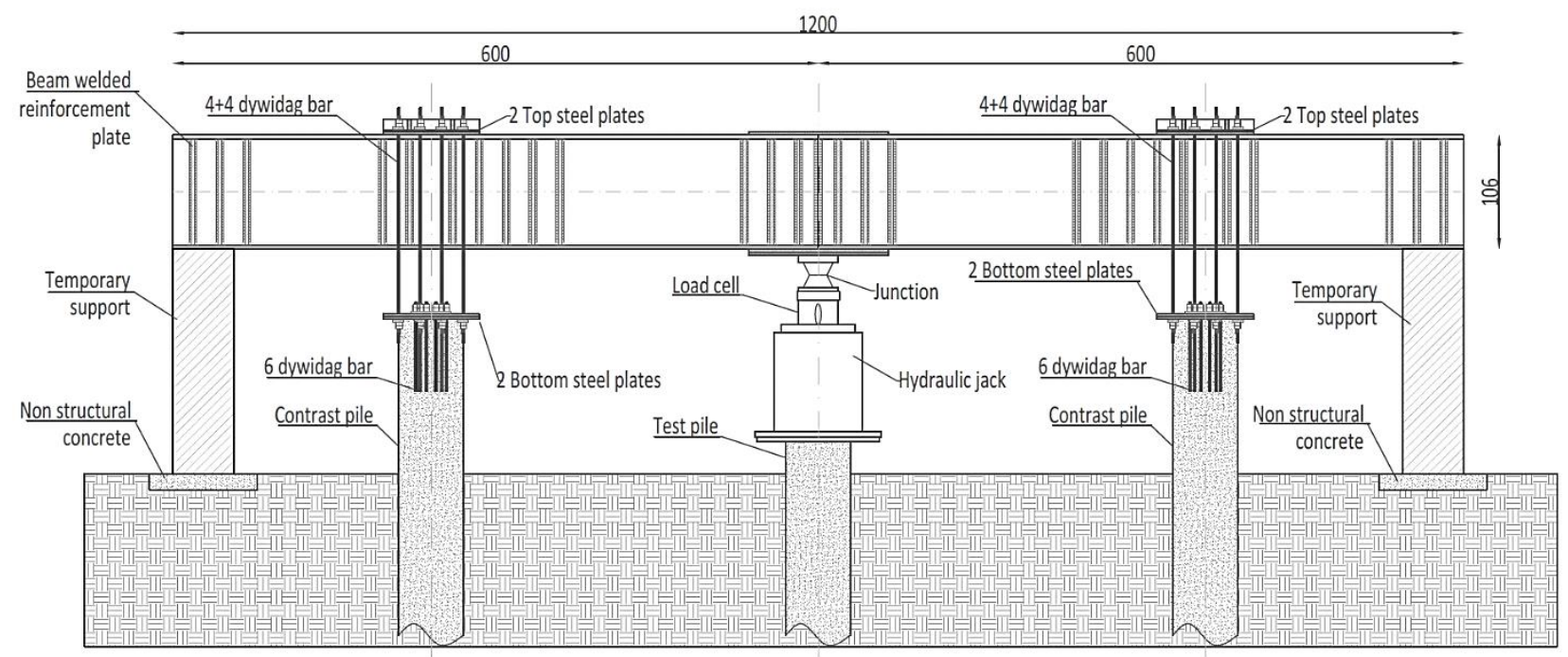

$\longrightarrow \frac{360}{360}$

(b)

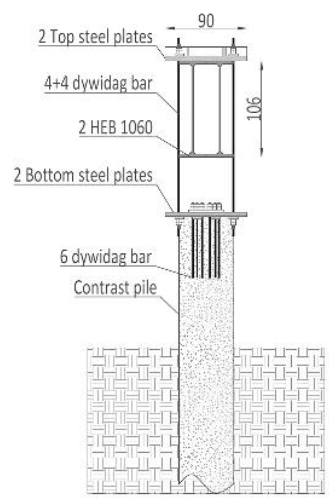

(c)

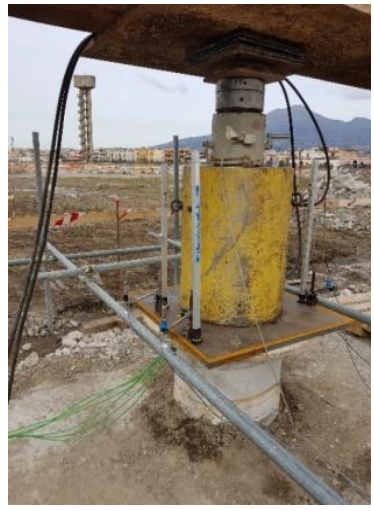

(d)

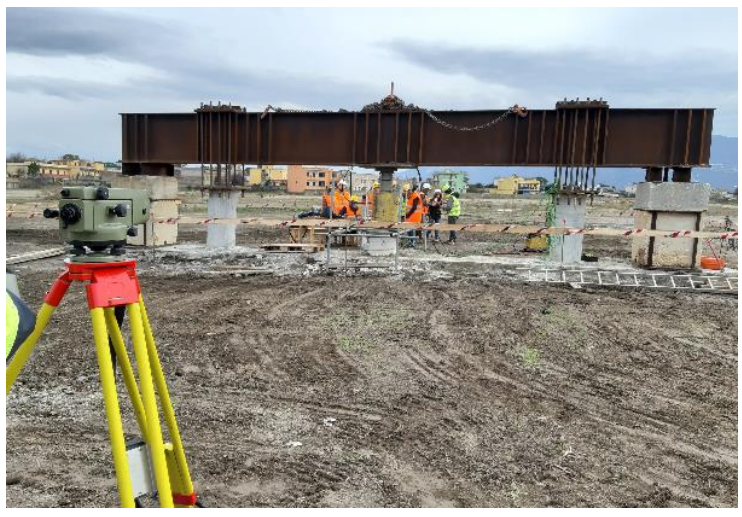

(e)

Figure 6. Layout of the test. (a) Plan view of the test layout, (b) section of the test layout A-A'; (c) section of the test layout B-B'; (d) test pile hydraulic jack, LVDTs and precision surveys and (e) tested pile and reaction system (beam anchored to the ground by two $0.60 \mathrm{~m}$ diameter tension piles).

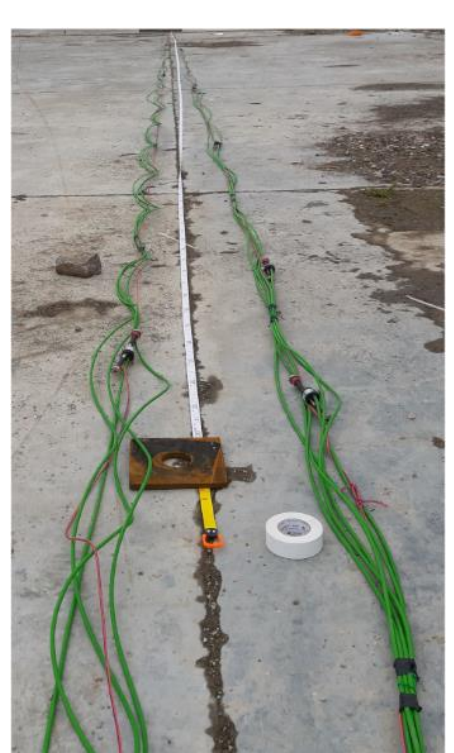

(a)

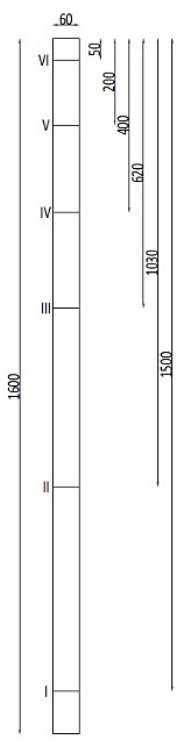

(b)

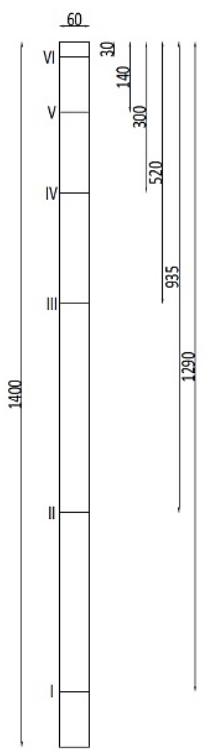

(c)

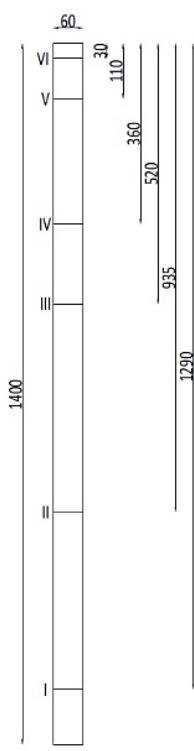

(d)

Figure 7. (a) Vibrating wire strain gauges fixed on the nylon wire before lowering down in the pile, locations of the gauges along the shaft of (b) Pile 9, (c) Pile 8 and (d) Pile 7 


\section{Test Results: Load-displacements Curves and Local Load Transfer}

The tests were carried out according to the Maintained Stage Loading procedure. Two loading and unloading cycles were performed. The first loading-unloading cycle consisted of six loading steps of 400 to $2400 \mathrm{kN}$ and three unloading steps of $800 \mathrm{kN}$. The second loading-unloading cycle was performed with variable loading increments in the range 400-800 kN until the design pile bearing capacity $(5000 \mathrm{kN})$ that was always exceeded. The duration of each loading step was variable with the aim to ensure that creep settlements were over (i.e. final settlement rate less than $0.003 \mathrm{~mm} / \mathrm{min}$ ). The maximum load and stress in the pile section and the final settlement at pile head recorded for the three pile tests are summarized in Table 2 .

Table 2. Summary of the load tests

\begin{tabular}{cccccc}
\hline Pile & $\mathbf{L}(\mathbf{m})$ & $\mathbf{D}(\mathbf{m})$ & Applied Load $(\mathbf{k N})$ & Settlement $(\mathbf{m})$ & Maximum stress in the pile section (MPa) \\
\hline Pile 9 & 16 & 0.60 & 6189 & 0,031 & 21,9 \\
Pile 8 & 14 & 0.60 & 5396 & 0,089 & 19 \\
Pile 7 & 14 & 0.60 & 5256 & 0,024 & 18,6 \\
\hline
\end{tabular}

The full load settlement relationships measured during the three design tests are presented in Figure 8.

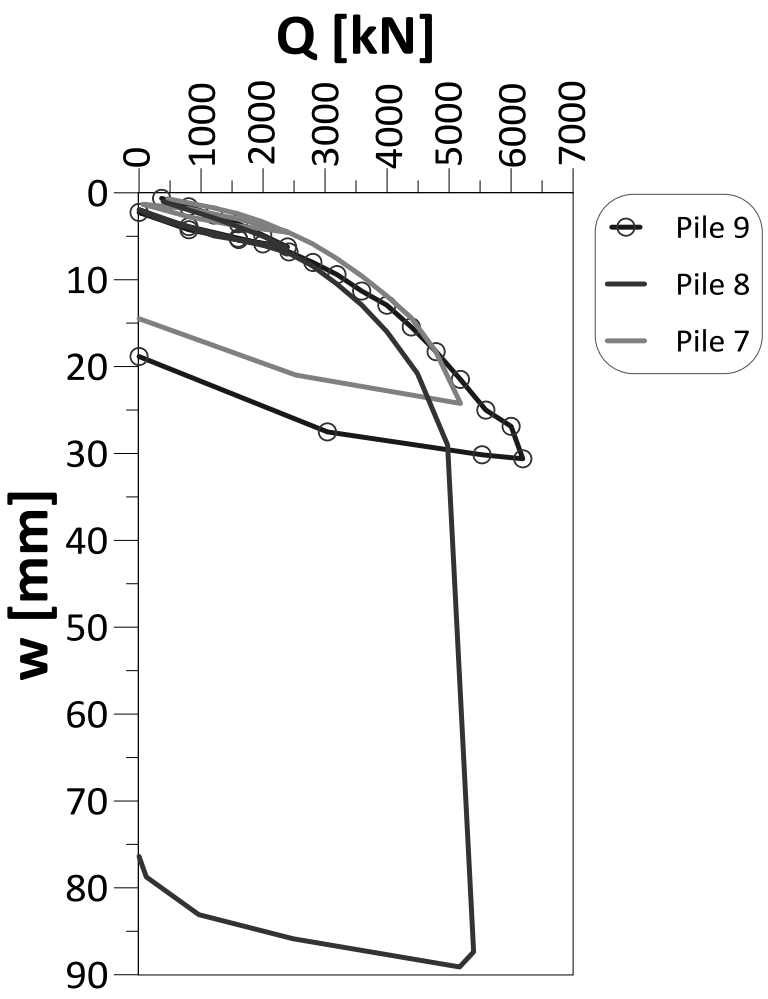

Figure 8. Load settlement relationship for Pile 9, Pile 8 and Pile 7

All the piles showed a very satisfactory performance, only the pile 8 approaching its ultimate load at about 5400 $\mathrm{kN}$. For both piles, 7 and 9, the maximum test load was not enough to activate all the components of the pile resistance. The load transfer curves for each pile and for all the loading steps are plotted in Figure 9. The values of the axial load were obtained simply multiplying the strains measured by the vibrating wire gauges times the axial stiffness EA of the pile. The area of the pile cross section A was considered constant along the pile depth while the young modulus, E, was computed as the ratio between the applied stress at pile head and the measured strain at the upper vibrating wire gage very close to the pile head.

The three piles show similar axial load transfer with the depth as could be noticed from Figure 9. In the case of both piles 7 and 9 , which were the far from showing failure at maximum load, the axial load transferred at the pile toe was only in the range of 7-8\% of the head load. In the case of Pile 8 at maximum test load about $22 \%$ of the head axial load is transferred down at the pile toe. 


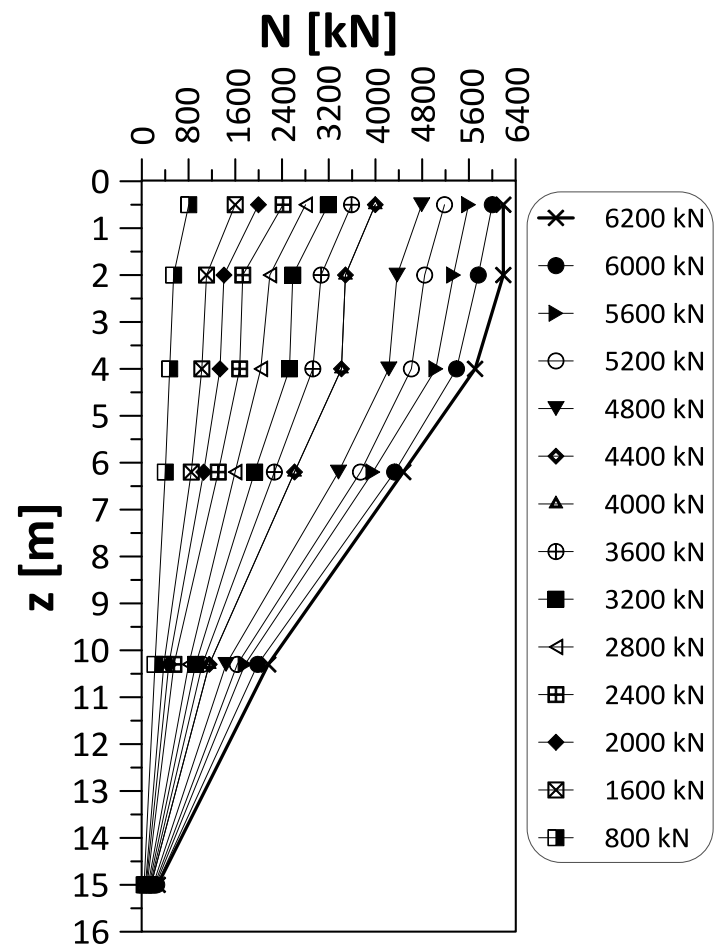

(a)

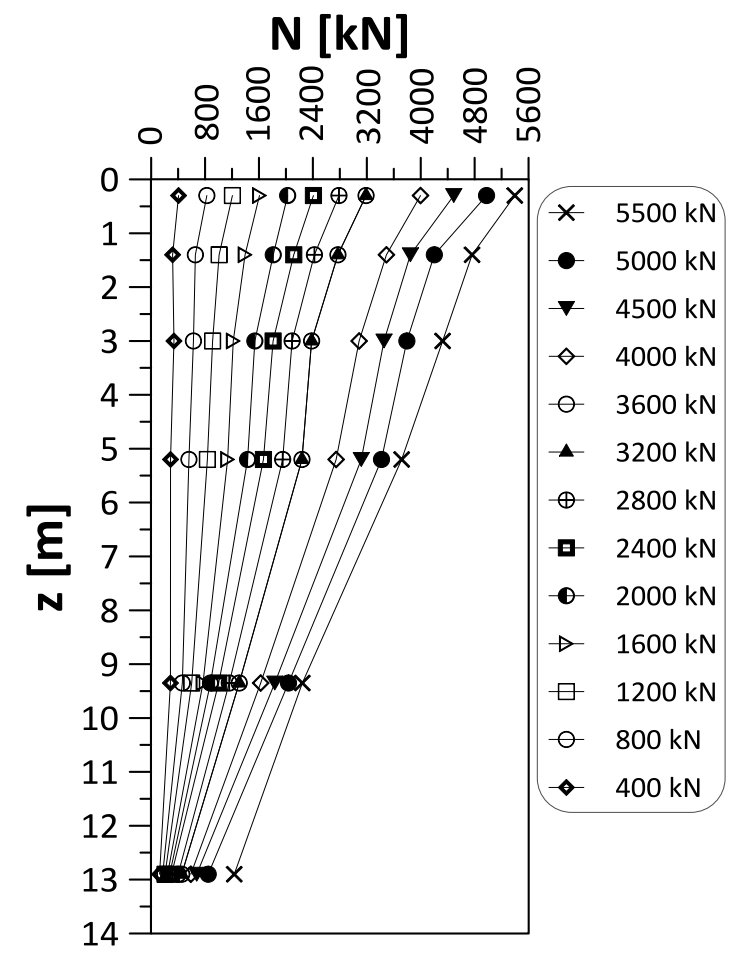

(b)

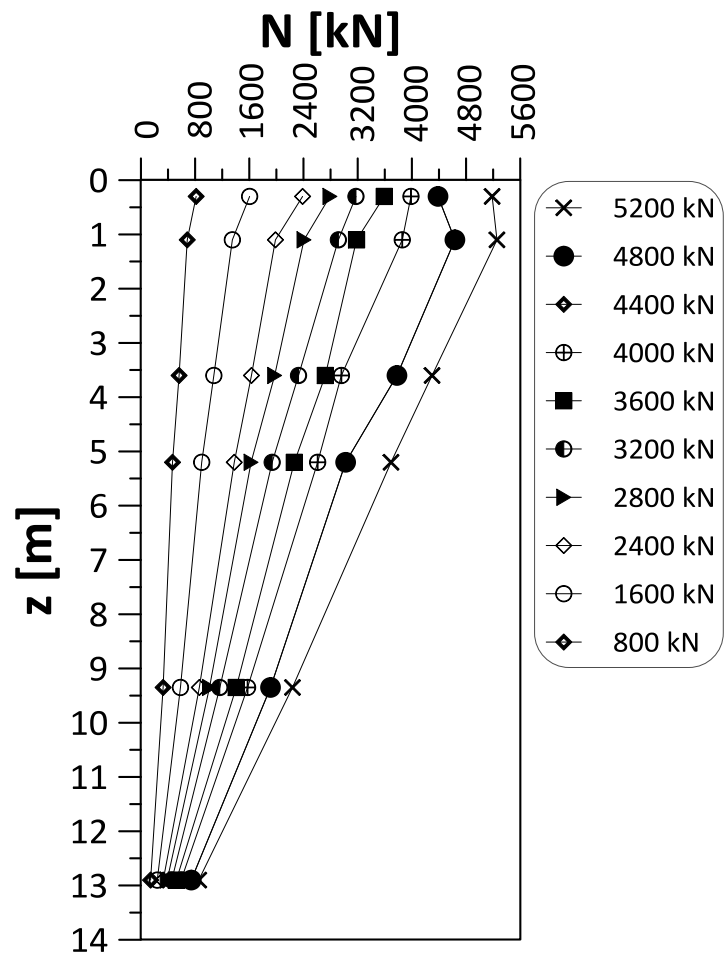

(c)

Figure 9. Axial load along shaft of (a) Pile 9, (b) Pile 8 and (c) Pile 7

From the axial load transfer of Figure 9 the $\tau$-w curves may be easily deduced by simple application of vertical equilibrium and strain compatibility (Figure 10 (a), (b) and (c)). The tip stress-displacement curves for all the tested piles are plotted in Figure 10 (d) showing the already mentioned difference between the Pile 8 and the other two piles. Furthermore, only for the Pile 8 the limiting value of the shaft friction was reached (see Figure $10 \mathrm{~b}$ ) while in the case of the Pile 9 and 7 it was not fully mobilised at the end of the tests. 


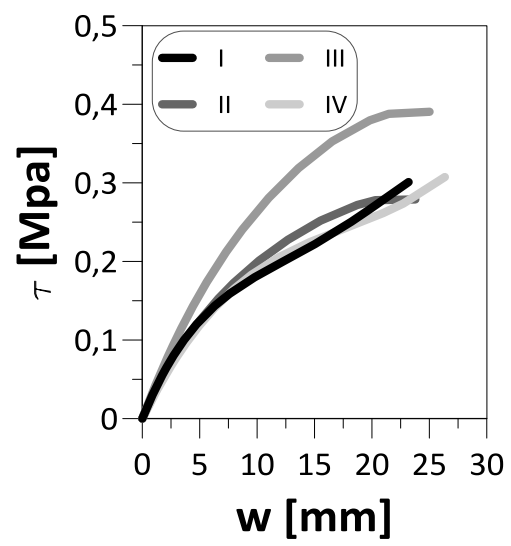

(a)

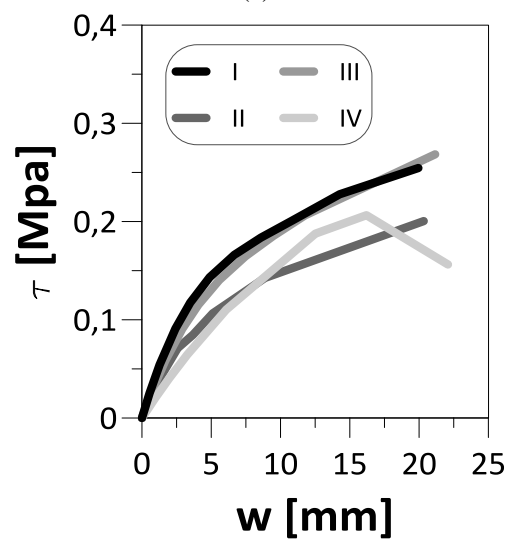

(c)

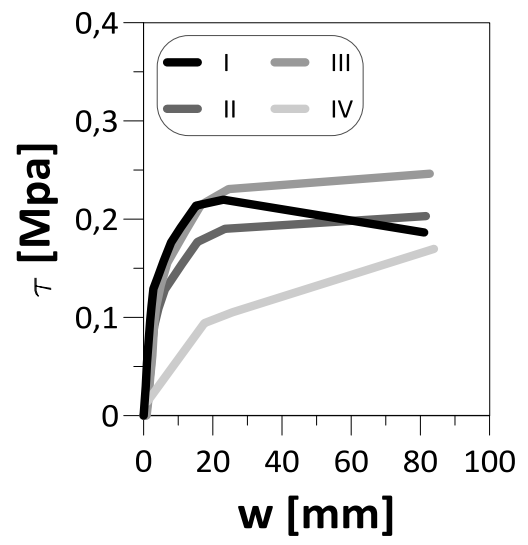

(b)

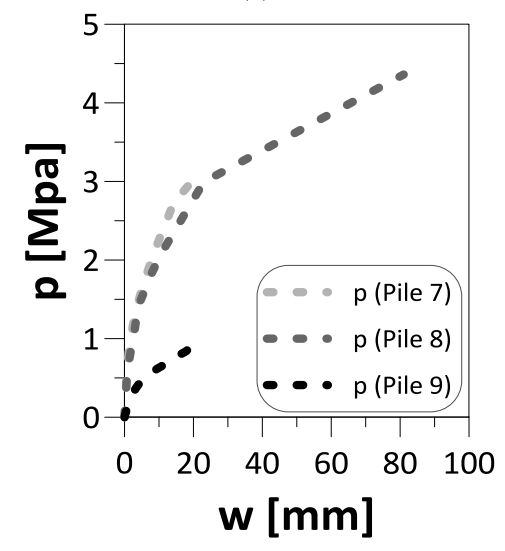

(d)

Figure 10. Load transfer curves at depths between I and II (I), II and III (II), III and IV (III), IV and V (IV) strain gauges for (a) Pile 9, (b) Pile 8 and (c) Pile 7. (d) Tip load-displacement curves for all the model piles

\section{Numerical Simulation of Hybrid Piles as Heat Exchangers for GSHP}

\subsection{Recent Trends in Numerical Simulation of Piles as Heat Exchangers}

At the design stage the use of piles as heat exchangers for Ground Source Heating Pump (GSHP) was considered as a sustainable choice for the air conditioning plant of the Maximall Pompeii. Mechanical loading tests were programmed and executed. The recorded experimental results presented in the previous sections were used for design purposes. On this basis, the longest pile i.e. Pile 9, $\mathrm{L}=16 \mathrm{~m}$, was selected as the right one, taking into account the live loads induced on the piled foundation by the superstructure. The evaluation of the performance under thermal loading was carried out by numerical simulations via the Finite Element Method (FEM). Two cases were analysed. In the first one the pile was simulated as a heat exchanger only in the lower $9 \mathrm{~m}$ stretch (Case A), while in the second one the pile was simulated as a heat exchanger for the whole shaft $16 \mathrm{~m}$ long (Case B). The numerical simulation compared to a field scale experiment was the most quick and cheap option considering that one year was considered as the minimum period to simulate at the design stage. In recent years, a large number of studies have been published and models of varying complexity have been implemented [14-21].

Saggu and Chakraborty (2015) investigated numerically the behaviour of geothermal energy piles in sand through the FE software Abaqus [18]. A parametric study was performed to investigate the effect of boundary conditions at the two pile extremities, the relative density of the soil, the initial lateral earth pressure coefficient $\mathrm{K}_{0}$ of the ground, the length and diameter of the pile, the type of thermal loading. In the case presented in the paper the hybrid new pile type, with the variable effects on the density of sand along the pile shaft induced by the particular tool adopted for the pile installation, has been investigated. The thermo-mechanical coupling was one of the main design issues. On this specific topic Yang et al. (2020) performed a parametric analysis investigating the influence on the pile performance (i.e. the pile head displacement) of the thermo-mechanical coupled loads, using FEM. They concluded that pile performance under combined thermo-mechanical loading is not the simple algebraic superposition of the purely thermal and mechanical performance [20].

\subsection{Model Parameters: Input Data and Calibration}

The FEM package PLAXIS 2D was demonstrated to be capable of modelling the most important features of the complex behaviour of a heat exchanger pile even with simple constitutive models for soil [22]. Validation of the fully 
coupled thermo-hydro-mechanical module of FE package was reported either by Maiorano et al. (2019) and by Russo et al. $(2019,2020)$ [22-24]. The main mechanical and geotechnical aspects of thermo-mechanical interaction are successfully reproduced using the software both in the case of field scale testing and of laboratory tests on small scale piles $[22,23]$.

In this study, the FE package PLAXIS 2D was used to simulate the behaviour of an isolated hybrid energy pile installed in pyroclastic sandy soils and subjected to both thermal and mechanical loadings. In the technical literature many studies are limited to permanent situations where only the maximum temperature variations are considered. In this study, according to the suggestions by Rammal et al. (2018) [17], transient thermo-hydro-mechanical coupled analyses were performed applying realistic thermal loadings to the pile.

Thermal loads on the piled foundations of a building whose indoor climate is governed by GSHP typically depend on its usage, geometry, human activities carried out and, very important, and its geographical location. To evaluate energy piles inlet temperatures in terms of magnitude and duration, a dynamic - even if simplified - simulation of the Mall was carried out with Design Builder software [25] modelling one year of operation. The modelled geothermal system was characterized by a heat exchanger primary circuit composed by a total length of about $1216 \mathrm{~m}$ of pipes. The so-called secondary circuit represents of course the indoor air conditioning plant of the building. The indoor air set point temperatures were fixed, according to UNI TS 11300 , at $20{ }^{\circ} \mathrm{C}$ for the winter season and $26{ }^{\circ} \mathrm{C}$ for the summer season. From a database implemented in the software, based on ASHRAE 2013 catalogue, the outdoor typical temperatures of the city of Napoli were uploaded in the model. Regarding the operation mode during the year, it was considered that the GSHP worked in a daily intermittent mode "on/off" mode from 8:00 a.m. to 22:00 p.m. for all days of the week. To simulate the activities carried out inside the building the software allowed the selection of several templates and the "Retail-Mall common area" was chosen in order to assign people density (people $/ \mathrm{m}^{2}$ ) and a time occupancy schedule of the area. In this simulation was found that the summer represented the most critical season in terms of highest energy peak demand (i.e. energy to cool the building). This last affirmation is in accordance with Morrone et al. (2014) that found, the ratio between the energy needed to cool the building in summer and the energy required for heating it in winter was in the range 2-2,5, for a building located in Napoli [26]. The annual simulation provided both the inlet temperatures in the piles and the indoor temperature of the Mall (Figure 11).

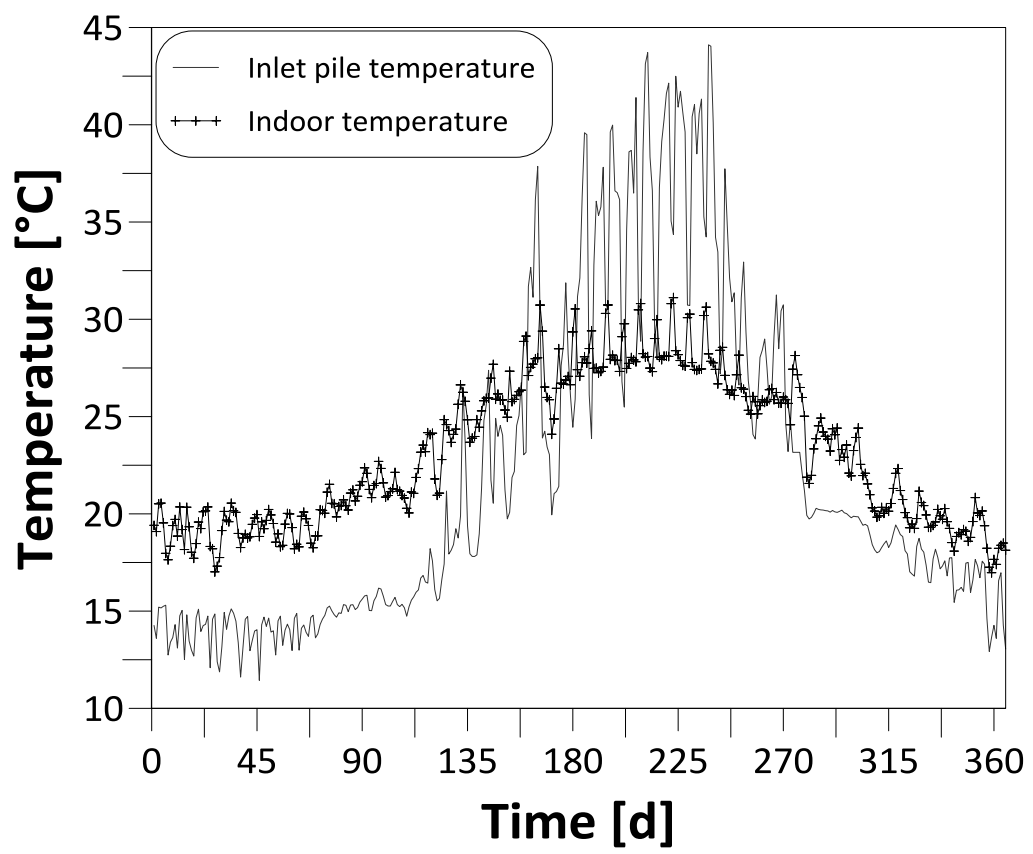

Figure 11. Results of the dynamic simulation. Inlet pile temperature variations and Indoor temperatures of the Mall during one year of operation

The mechanical behaviour observed during the load test on Pile 9 and described in the previous section and the site and laboratory geotechnical investigations were used for calibrating the strength and the stiffness parameters of the pile-soil model. A fine triangular mesh of 15-noded elements was used to discretize the axisymmetric model. Around the pile an additional mesh refinement was assigned to provide more accurate results. For the five layers of pyroclastic soil the Hardening Soil, (H-S), constitutive model was adopted, while, for the pile the simple linear elastic model was used. The Young's modulus of the concrete pile was fixed at 30.000 MPa. Interface elements have been adopted to allow vertical relative displacements between the pile and the surrounding soil. For these elements, the same strength parameters of the surrounding soil were kept for all the soil layers. 
The hybrid pile execution with a high displacement level in the upper soil was simulated by assuming a very high value of the stress ratio $K_{0}=\sigma_{h} / \sigma_{v}=4$. Typical value of $K_{0}$ in the undisturbed soil are estimated by means of Jaky formula, $\mathrm{K}_{0}=1$-sen $\phi$, which in this case are about 0.5 . The value of 4 is just taken to simulate the horizontal stress increase due to the large stem pipe used in the upper half of the pile. The dilatancy angles, $\psi$, are estimated from the peak friction angles reported in Table 1 using Bolton (1986) [27] expression and an upper bound of $4^{\circ}$ was adopted. The H-S model allows accounting for stress dependent stiffness according to a power law, through an input parameter $m$. As suggested by Brinkgreve et al. (2010), a realistic choice for soft soil is the assumption of a linear relationship, i.e. $m=1$. The ratio among the values of the $\mathrm{E}_{50}$ and $\mathrm{E}_{\mathrm{ur}}$ moduli were kept equal to the suggested value $\mathrm{E}_{50}=\mathrm{E}_{\mathrm{ur}} / 3$ [28]

A classical best fit procedure based on the trial and error method was adopted to obtain the set of stiffness parameters listed in Table 3 . The secant stiffness values $\left(E_{50}\right)$ obtained from the calibration procedure are slightly larger than those reported as Es in Table 1 at least for the bottom layers.

Table 3. Stiffness and resistance parameters used for the hardening soil model

\begin{tabular}{|c|c|c|c|c|c|c|c|}
\hline \multirow{2}{*}{ Soil Type } & \multicolumn{2}{|c|}{ Depth } & \multirow{2}{*}{$\begin{array}{c}\mathbf{X} \\
\left(\mathbf{k N} / \mathbf{m}^{3}\right)\end{array}$} & \multirow{2}{*}{$\begin{array}{c}\varphi \\
\left({ }^{\circ}\right)\end{array}$} & \multirow{2}{*}{$\begin{array}{l}\psi \\
\left(^{\circ}\right)\end{array}$} & \multirow{2}{*}{$\begin{array}{c}\mathbf{E}_{50} \\
(\mathbf{M P a})\end{array}$} & \multirow{2}{*}{$\begin{array}{c}\mathbf{E}_{\mathrm{ur}} \\
(\mathbf{M P a})\end{array}$} \\
\hline & Top (m) & Bottom (m) & & & & & \\
\hline US & 0 & 1 & 18 & 30 & - & 10 & 30 \\
\hline $\mathrm{P} 1$ & 1 & 3 & 16 & 32 & 2 & 20 & 60 \\
\hline SG & 3 & 10 & 17,5 & 35 & 4 & 70 & 210 \\
\hline $\mathrm{P} 2$ & 10 & 12 & 16 & 32 & 2 & 80 & 240 \\
\hline FS & 12 & 22 & 17 & 35 & 4 & 100 & 300 \\
\hline
\end{tabular}

\subsection{Results of Thermo-mechanical Numerical Analysis}

In Figure 12 the load-settlement curves (a) and the axial load transfer along the pile shaft (b) obtained by PLAXIS code at the end of the calibration procedure are compared with the experimental curves. The comparison shows that the agreement with the experiment is rather satisfactory both in term of load-settlement and load transfer. The general trend of both the primary loading and unloading-reloading branches is satisfactory reproduced by the H-S model that allows a good fitting particularly in the first loading - unloading branch (Figure 12(a)). The axial load profiles along the pile shaft, calculated by the FE simulation (PLAXIS 2d) and measured during the experimental test (Experimental), are reported for two different loading steps, i.e. $40 \%$ of the ultimate test load, assumed as live load for the pile, and ultimate load. The comparison is rather satisfactory in both cases the agreement being a little better at live load.

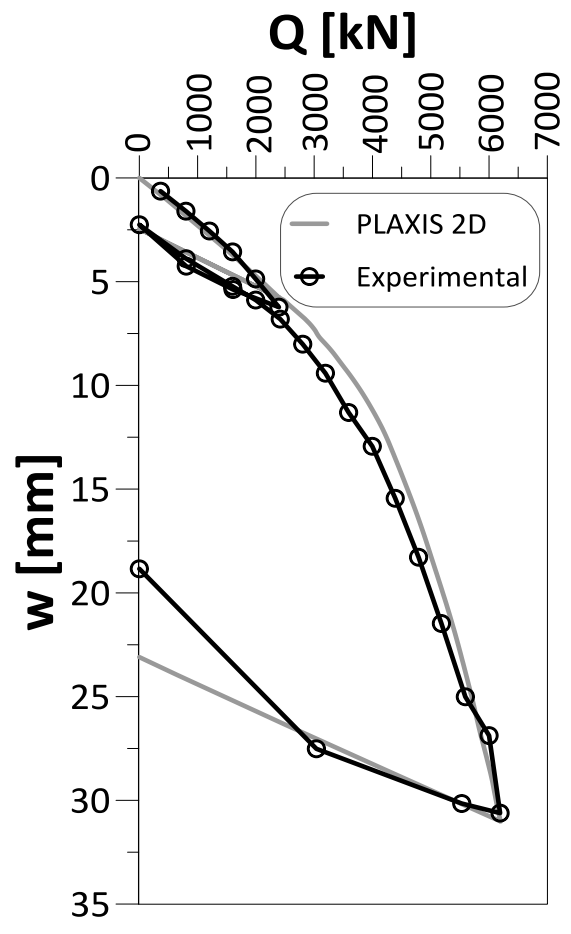

(a)

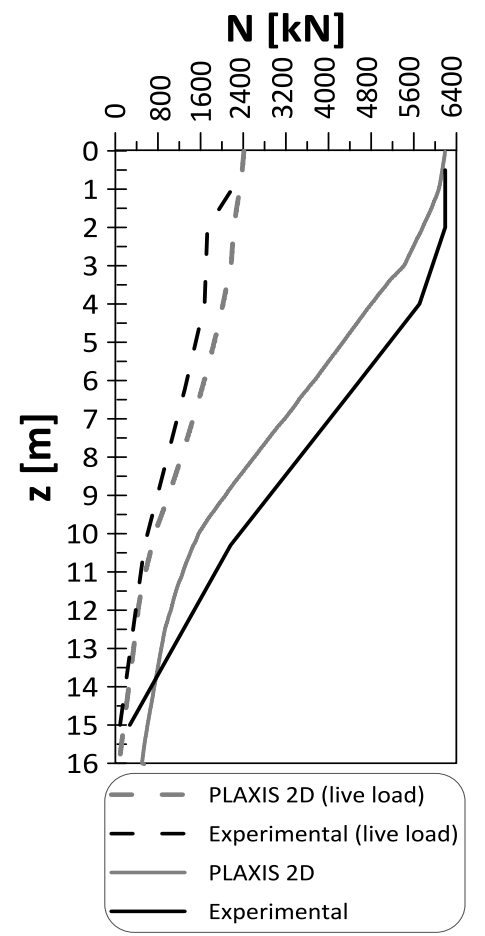

(b)

Figure 12. Experimental and numerical (PLAXIS 2D) results. (a) Load-settlement relationship and (b) axial load along pile shaft during live load and ultimate condition 
Pile 9 is the longest tested pile and was selected as the design choice for the foundation of the Mall because of its satisfactory mechanical performance. However Pile 9, with its $16 \mathrm{~m}$ long shaft, was more efficient compared to the other two shorter piles also by a thermal point of view. As widely known the upper 6-8 $\mathrm{m}$ of soil have a highly variable temperature during the year while in the zone below, so-called Deep zone, the temperature profile is nearly constant. For this reason, generally the heat flow from the pile to the soil is larger and more stable in the lower stretch of the pile shaft. Among the main concerns when designing piles as heat exchangers are those related to the movements or the stress close to the pile head and its consequence on the geotechnical performance. Either to use the most efficient thermal part of the pile and to reduce the effects at the pile head a simulation where only the bottom $9 \mathrm{~m}$ of the pile are used as heat exchanger was first carried out (Case A). A comparison with a pile exchanging heat along the whole shaft (Case B), which is a more conventional choice, is then shown and one year of operational condition is simulated.

First of all, an axial load corresponding to the live load equal to $40 \%$ of the maximum test load was applied in the simulation. Thermal loadings were imposed as the temperature-time variable function plotted in figure 11 as inlet pile temperature. In figure 13 a cross section of the FEM model with the thermal boundary conditions is sketched and the two analysed cases, A and B, are also outlined.

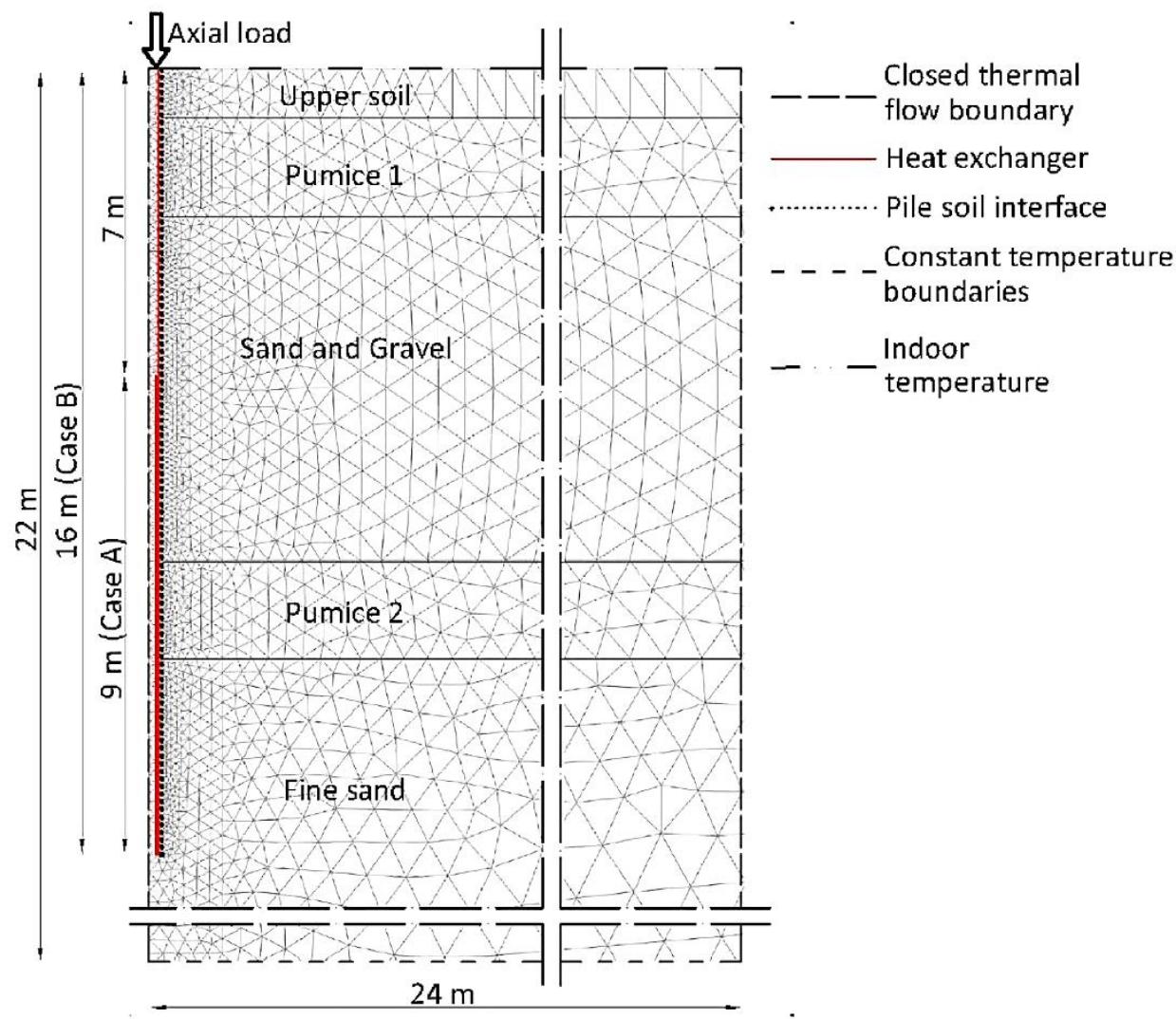

Figure 13. FE model and thermal boundary conditions

At the ground surface a convection boundary condition with an appropriate heat transfer coefficient was assigned to model. The thermal interaction between the upper structure and the geothermal system was simulated considering that at the top of the model the indoor temperatures of the Mall center, computed through dynamic energy simulations (Figure 11), were applied [24]. Closed flow boundary thermal conditions are assigned at the sides of the model, while at the bottom a constant temperature condition was set, corresponding to the Deep zone stable ground temperature The Deep zone soil temperature was fixed at $17{ }^{\circ} \mathrm{C}$ that corresponds to the average shallow groundwater temperature in Naples. The thermal properties of the soil are those typical of saturated pyroclastic sandy soils [29, 30]. i.e. thermal conductivity of $2.4 \mathrm{~W} / \mathrm{m} \mathrm{K}$ and heat capacity of $880 \mathrm{~J} / \mathrm{kg} \mathrm{K}$. For the concrete pile, a thermal conductivity of $2.3 \mathrm{~W} / \mathrm{m}$ $\mathrm{K}$, a heat capacity of $800 \mathrm{~J} / \mathrm{kg} \mathrm{K}$ and a linear expansion coefficient of $1 \times 10^{-5}{ }^{\circ} \mathrm{C}^{-1}$ were adopted.

First of all the temperatures calculated along the concrete pile are reported at different depths in figure 14 for the Case A. In the Case A, the Figure 14, shows that temperature variations along pile shaft are of course in the range fixed by the two assigned boundary conditions i.e. the bottom heat exchanger circuit and the top building indoor temperature. 


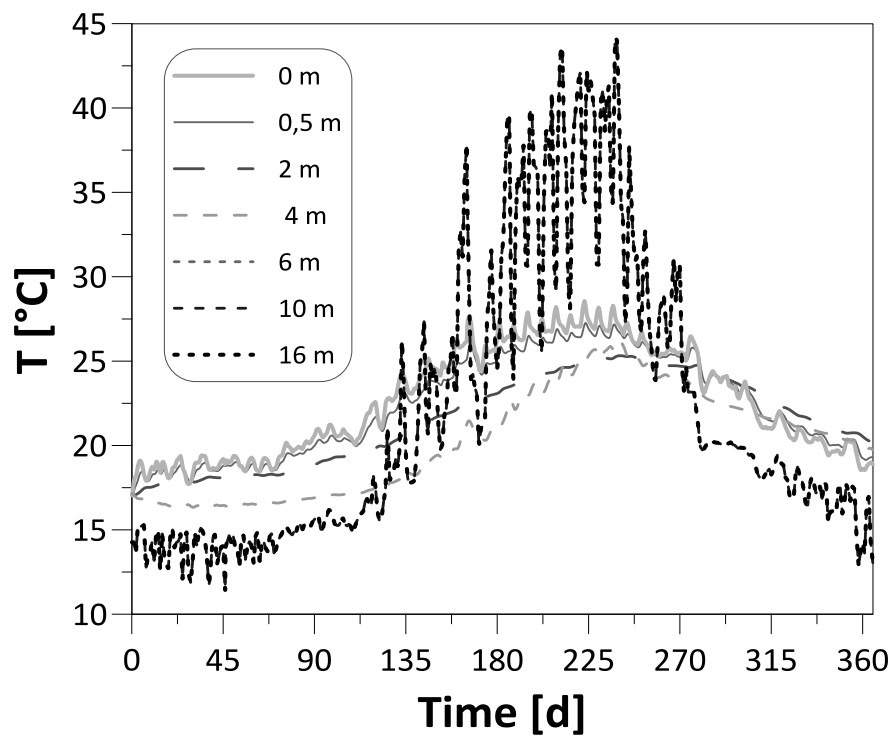

Figure 14. Temperatures variations at different depths from pile head during the yearly thermal cycle for Case A

For the Case B the temperature plot is not reported because it is rather intuitive that the dotted profile at $16 \mathrm{~m}$, (Figure 14), keeps exactly the same for all the above sections. Pile head and toe displacements during one year of operation are plotted in Figure 15 (a). The axial load along the pile shaft is plotted versus the depth $\mathrm{z}$ at different stages of the yearly thermal operational cycle: (Figure 15 (b)).

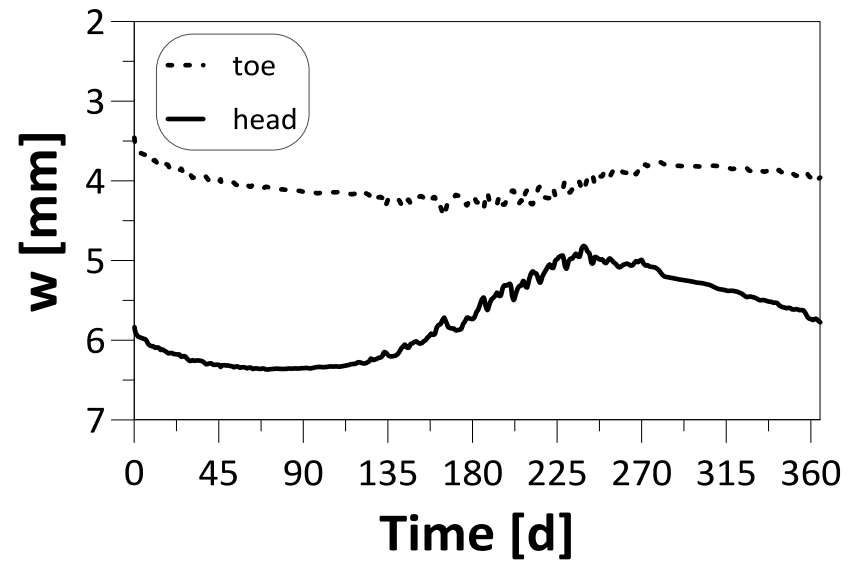

(a)

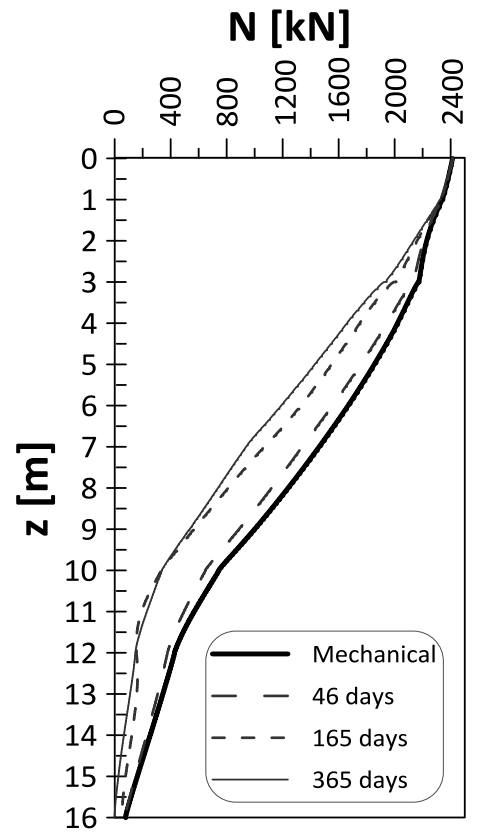

(b)

Figure 15. Results of numerical simulations for Case A. (a) Pile head and toe thermo-mechanical displacements during yearly operation, (b) axial load along pile shaft under the live load (mechanical), live load and cooling (46 days), live load and heating (165 days) and at the end of thermal cycle (365 days).

The displacement plot shows that under live load, $(\mathrm{T}=0$ day $)$, the settlement at pile head is around $6 \mathrm{~mm}$ while, because of pile compressibility, the settlement at pile toe is only $3.5 \mathrm{~mm}$, (i.e. about $2.5 \mathrm{~mm}$ of pile shortening). The pile toe, which is embedded in a rather stiff soil layer, show very little movements due to the temperature variation during one year of operation. On the other hand, the pile head shows a maximum upward movement of $1.5 \mathrm{~mm}$ which is about $20 \%$ of the settlement under mechanical load. In Figure 15 (b) it can be appreciated that one year of operation changes significantly also the way in which the top mechanical live load is transferred down along the pile shaft. It is evident that the thermal yearly cycle increases the percentage of load transferred to the surrounding soil in the upper layers reducing consequently the load transferred in the vicinity of the pile toe. This information is in good agreement with the small movement of the pile toe in the Figure 15 (a).

The analyses carried out on the pile Case B (i.e. pile as heat exchanger along the whole shaft) allow a comparison with the Case A both by a thermal and by a geotechnical point of view. 
In Figure 16 (a) both the head and the toe pile dimensionless displacements during the thermal yearly cycle are plotted. The dimensionless quantity on the $\mathrm{y}$ axis is the ratio of the additional displacement, $\mathrm{w}_{\mathrm{T}}$, induced by the thermal loading, divided by the settlement, $w_{M}$, induced by the mechanical live load. In Figure 16 (a), upward displacements are plotted as negative while downward movements are plotted as positive. It can be appreciated that in the Case A both the settlements of the pile head and of the pile toe are less than the corresponding quantities in the Case B (Figure 16 (a)). Even more significant is the fact that the residual movement at the piled head at the end of the year is nearly zero in the Case A, while it is close to $+20 \%$ in the Case B. Taking into account that the ordinary life of a Mall is generally in the range from 30 to 50 years the likely settlement accumulated in the case B is very significant and can be a problem for the pile as a foundation system of the above superstructure. In terms of axial loading the two cases are compared with normalized curves in the Figure 16 (b). The normalized axial loading on the $\mathrm{x}$ axis of Figure 16 (b) is simply the ratio of the axial loading along the shaft divided by the corresponding axial load at the pile head. The comparison between the two cases in terms of load transfer along the pile shaft is plotted at 46 day (cooling phase), 165 day (heating phase) and at the end of the thermal cycle (365 days). The differences between the two cases are less significant than those in terms of settlement but, however, it can be appreciated that the Case A is more efficient in redistributing the load transfer along the shaft when compared to the Case B for both heating and cooling modes.

The numerical analyses carried out allow a comparison in terms of thermal performance and the magnitude of heat transfer along the pile and towards the surrounding soil. The heat transfer process is basically a radial one from the interior of the pile to the surrounding soil. The horizontal component of the flux is by far the most important, and the calculations, even for simplicity, have been limited to this quantity. Thermal performances for Case A were evaluated in terms of mean specific heat extraction/injection rate per meter of equipped pile, at different stages of the thermal cycle. After 165 days, in the middle of the main heating phase, the specific heat injection was about $295 \mathrm{~W} / \mathrm{m}$. In Case $\mathrm{B}$, the magnitude of the average specific heat injection decreases by about $9 \%$ with respect to Case A. At 165 days, the mean heat extraction rate per meter of equipped pile is about $277 \mathrm{~W} / \mathrm{m}$ for Case B. More precisely, the mean heat extraction rate in the first $7 \mathrm{~m}$ of equipped pile is $268 \mathrm{~W} / \mathrm{m}$ while in the bottom $9 \mathrm{~m}$ of the energy pile the heat injection is about $284 \mathrm{~W} / \mathrm{m}$. The heat exchange observed during the year for the two cases is, of course, influenced by the ground surface thermal boundary condition [31]. The assumption made in the calculations tries to simulate the heat transfer from the indoor environment of the mall to the pile foundation, which usually occurs through the structural slab connecting the head of the piles. Another widely adopted assumption in the research reported in the literature is to simply assume the outdoor temperature of the geographic location as the ground surface boundary condition. The real behavior of any energetic foundation system may be considered somewhat intermediate between the two mentioned boundary conditions [14]. For completeness, two FE simulations were carried out for the two piles (Case A and Case $\mathrm{B}$ ), assuming as ground surface thermal condition the outdoor temperature of the considered geographic location. The calculated results show that for Case A, after 165 days from the start of the thermal cycle, the specific heat injection was about $310 \mathrm{~W} / \mathrm{m}$. The same quantity evaluated at 46 days and 365 days was about 70 and $60 \mathrm{~W} / \mathrm{m}$, respectively. For Case B, after 165 days, the specific heat injection was about $275 \mathrm{~W} / \mathrm{m}$ and at 46 and 365 days, $54 \mathrm{~W} / \mathrm{m}$ and 42 $\mathrm{W} / \mathrm{m}$ were calculated, respectively. With the new assumption as the boundary condition, the differences between the two cases are enhanced. The case A (i.e., the pile equipped with pipes in the bottom $9 \mathrm{~m}$ ) is by far more efficient in the thermal exchange, the largest difference being of the order of $50 \%$ at the end of the simulated year.

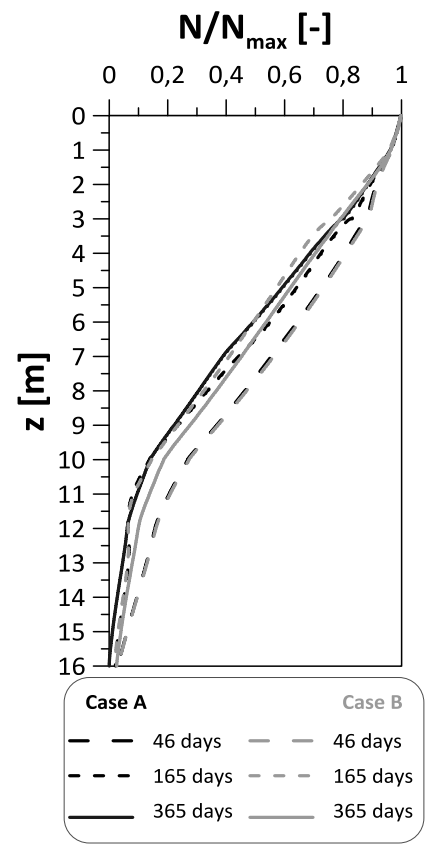

(b)

Figure 16. Comparison between Case A and B. (a) Dimensionless displacements at toe and head of pile versus time and (b) dimensionless axial loading along pile shaft after 46 days, 165 days and at the end of thermal cycle (365 days). 


\section{Conclusion}

In the paper, a new installation procedure for a foundation pile of a new mall under design in a disused factory area is first presented. Generally, piles are classified as displacement or replacement (BS EN 12699:2015). The newly conceived pile is a hybrid intermediate pile. The upper portion of the pile is installed in a shallow and thus contaminated but rather loose sandy layer using a displacement tool, while the lower portion of the pile is installed in clean and dense sand via a small stem auger, which is a classical replacement tool that takes away the soil that will be replaced by the concrete. The mechanical performance of the pile was measured via loading tests where three different piles were compared. The design of the foundation system of the Mall was based on the results of these loading tests, taking into account that this is a procedure allowed by many international codes (EN 1997 or EuroCode 7 on geotechnical structures) and national regulations. Among the three tested piles, only one was selected as a candidate for the design of the overall foundation system. The settlement of the selected pile under live load was considered extremely satisfactory while the soil removed during the pile installation, coming only from the deep soil layers, was not polluted. At the design stage, the possibility of installing pipes for circulating fluid inside the piles, such as to use the pile itself as a heat exchanger with a Ground Source Heating Pump system, was considered. The so-called Energy Piles were introduced nearly 30 years ago and their use as a renewable energy source in the framework of sustainable development of the construction industry has been constantly growing over the years. The numerical analysis developed in the paper is dedicated to this aspect and to the performance of the pile under thermo-mechanical combined loading. Both the mechanical and thermal aspects of the performance have been carefully investigated. The comparison between a more conventional energy pile exchanging heat along the whole shaft (Case B) and a "smarter" energy pile exchanging heat only in the lower stretch (Case A) shows that the "smarter" pile performs better as a foundation system, reducing the amount of thermal movement which will be eventually transmitted to the above building. The better performance is confirmed for Case A also from the thermal point of view because of the greater efficiency in exchanging heat with the ground in the soil layers far from the ground surface.

\section{Declarations}

\subsection{Author Contributions}

G.R., G.M. and L.D.G. contributed to the design and implementation of the research, to the analysis of the results and to the writing of the manuscript. All authors have read and agreed to the published version of the manuscript.

\subsection{Data Availability Statement}

The data presented in this study are available in article.

\subsection{Funding}

The authors received no financial support for the research, authorship, and/or publication of this article.

\subsection{Institutional Review Board Statement}

Not applicable.

\subsection{Informed Consent Statement}

Not applicable.

\subsection{Declaration of Competing Interest}

The authors declare that there is no conflict of interests regarding the publication of this manuscript. In addition, the ethical issues, including plagiarism, informed consent, misconduct, data fabrication and/or falsification, double publication and/or submission, and redundancies have been completely observed by the authors.

\section{References}

[1] Zhang, H., Ma, D., Qiu, R., Tang, Y., \& Du, C. (2017). Non-thermal plasma technology for organic contaminated soil remediation: A review. Chemical Engineering Journal, 313, 157-170. doi:10.1016/j.cej.2016.12.067.

[2] Khalid, S., Shahid, M., Niazi, N. K., Murtaza, B., Bibi, I., \& Dumat, C. (2017). A comparison of technologies for remediation of heavy metal contaminated soils. Journal of Geochemical Exploration, 182, 247-268. doi:10.1016/j.gexplo.2016.11.021.

[3] Cioffi, R., Colangelo, F., Pertis, M. De, \& Beneduce, A. (2013). La bonifica di siti contaminati da amianto: il caso ex Rhodiatoce.

[4] Yao, Z., Li, J., Xie, H., \& Yu, C. (2012). Review on Remediation Technologies of Soil Contaminated by Heavy Metals. Procedia Environmental Sciences, 16, 722-729. doi:10.1016/j.proenv.2012.10.099. 
[5] Peng, C., Chen, W., Liao, X., Wang, M., Ouyang, Z., Jiao, W., \& Bai, Y. (2011). Polycyclic aromatic hydrocarbons in urban soils of Beijing: Status, sources, distribution and potential risk. Environmental Pollution, 159(3), 802-808. doi:10.1016/j.envpol.2010.11.003.

[6] Brandl, H. (2006). Energy foundations and other thermo-active ground structures. Geotechnique, 56(2), 81-122. doi:10.1680/geot.2006.56.2.81.

[7] Gibbs, H. J., \& Holtz, W. G. (1957). Research on determining density of sands by Spoon Penetration Standart. 4th Int. Conf. Soil Mech. Found. Eng., London, 1, 35-39.

[8] Kulhawy, F. H., \& Mayne, P. W. (1990). Manual on estimating soil properties for foundation design (No. EPRI-EL-6800). Electric Power Research Inst., Palo Alto, CA (USA); Cornell Univ., Ithaca, NY (USA). Geotechnical Engineering Group.

[9] API, (1987). Recommended practice for planning, designing, and constructing fixed offshore platforms. API RP2A, 17th edition. American Petroleum Institute, Washington, DC.

[10] Schmertmann, J. H. (1979). Statics of SPT. Journal of the Geotechnical Engineering Division, 105(5), 655-670. doi:10.1061/ajgeb6.0000801.

[11] Beer, D. (1965). Bearing capacity and settlement of shallow foundation on sand. In Proc. Symp. Bearing capacity and settlement of foundations (pp. 15-33).

[12] Russo, G. (2012). Experimental investigations and analysis on different pile load testing procedures. Acta Geotechnica, 8(1), 17-31. doi:10.1007/s11440-012-0177-4.

[13] Russo, G. (2004). Full-scale load tests on instrumented micropiles. Proceedings of the Institution of Civil Engineers: Geotechnical Engineering, 157(3), 127-135. doi:10.1680/geng.2004.157.3.127.

[14] Bourne-Webb, P., Burlon, S., Javed, S., Kürten, S., \& Loveridge, F. (2016). Analysis and design methods for energy geostructures. Renewable and Sustainable Energy Reviews, 65, 402-419. doi:10.1016/j.rser.2016.06.046.

[15] Di Donna, A., \& Laloui, L. (2015). Response of soil subjected to thermal cyclic loading: Experimental and constitutive study. Engineering Geology, 190, 65-76. doi:10.1016/j.enggeo.2015.03.003.

[16] Laloui, L., Nuth, M., \& Vulliet, L. (2006). Experimental and numerical investigations of the behaviour of a heat exchanger pile. International Journal for Numerical and Analytical Methods in Geomechanics, 30(8), 763-781. doi:10.1002/nag.499.

[17] Rammal, D., Mroueh, H., \& Burlon, S. (2018). Impact of thermal solicitations on the design of energy piles. Renewable and Sustainable Energy Reviews, 92, 111-120. doi:10.1016/j.rser.2018.04.049.

[18] Saggu, R., \& Chakraborty, T. (2015). Thermal analysis of energy piles in sand. Geomechanics and Geoengineering, 10(1), 1029. doi:10.1080/17486025.2014.923586.

[19] Sutman, M., Speranza, G., Ferrari, A., Larrey-Lassalle, P., \& Laloui, L. (2020). Long-term performance and life cycle assessment of energy piles in three different climatic conditions. Renewable Energy, 146, $1177-1191$. doi:10.1016/j.renene.2019.07.035.

[20] Yang, W., Zhang, L., Zhang, H., Wang, F., \& Li, X. (2020). Numerical investigations of the effects of different factors on the displacement of energy pile under the thermo-mechanical loads. Case Studies in Thermal Engineering, 21, 100711. doi:10.1016/j.csite.2020.100711.

[21] Rotta Loria, A. F., Donna, A. Di, \& Laloui, L. (2015). Numerical Study on the Suitability of Centrifuge Testing for Capturing the Thermal-Induced Mechanical Behavior of Energy Piles. Journal of Geotechnical and Geoenvironmental Engineering, 141(10), 04015042. doi:10.1061/(asce)gt.1943-5606.0001318.

[22] Maiorano, R. M. S., Marone, G., Russo, G., \& Di Girolamo, L. (2019). Experimental behavior and numerical analysis of energy piles. 17th European Conference on Soil Mechanics and Geotechnical Engineering, ECSMGE 2019 - Proceedings, 2019-September. doi:10.32075/17ECSMGE-2019-0819.

[23] Russo, G., Maiorano, R. M. S., \& Marone, G. (2019). Analysis of thermo-mechanical behaviour of energy piles. Geotechnical Engineering, 50(3), 110-117.

[24] Russo, G., Marone, G., Di Girolamo, L., \& Pirone, M. (2020). Numerical Prediction of Thermo-Mechanical Behavior of Energy Pile in Pyroclastic Soil. Sustainable Civil Infrastructures, 89-107. doi:10.1007/978-3-030-34193-0_7.

[25] DesignBuilder (2021). Help - Internal Mass. Available online: http://designbuilder.co.uk/helpv7.0/\#Internal_Mass.h tm?Highlight= zonecapacitance multiplier (Accessed on March 2021).

[26] Morrone, B., Coppola, G., \& Raucci, V. (2014). Energy and economic savings using geothermal heat pumps in different climates. Energy Conversion and Management, 88, 189-198. doi:10.1016/j.enconman.2014.08.007. 
[27] A Bolton, M. D. (1986). The strength and dilatancy of sands. Géotechnique, 36(1), 65-78. doi:10.1680/geot.1986.36.1.65.

[28] Brinkgreve, R. B. J., Engin, E., \& Engin, H. K. (2010). Validation of empirical formulas to derive model parameters for sands. Numerical Methods in Geotechnical Engineering - Proceedings of the 7th European Conference on Numerical Methods in Geotechnical Engineering, 137-142. doi:10.1201/b10551-27.

[29] Colombo, G. (2010). Il congelamento artificiale del terreno negli scavi della metropolitana di Napoli : valutazioni teoriche e risultati sperimentali. In Rivista italiana di geotecnica, Vol. 4, pp. 42-62.

[30] McCombie, M. L., Tarnawski, V. R., Bovesecchi, G., Coppa, P., \& Leong, W. H. (2017). Thermal Conductivity of Pyroclastic Soil (Pozzolana) from the Environs of Rome. International Journal of Thermophysics, 38(2). doi:10.1007/s10765-016-2161-y.

[31] Fadejev, J., Simson, R., Kurnitski, J., \& Haghighat, F. (2017). A review on energy piles design, sizing and modelling. Energy, 122, 390-407. doi:10.1016/j.energy.2017.01.097. 